\title{
非正規確率変数の同時確率密度関数を用いた基準強度の算定 \\ CALCULATION OF REFERENCED STRENGTH BY JOINT PROBABILITY DENSITY FUNCTION OF NON-NORMAL RANDOM VARIABLES
}

\author{
中村 昇*, 堀 江 和 美**, 飯 島 泰 男*** \\ Noboru NAKAMURA, Kazumi HORIE and Yasuo IIJIMA
}

\begin{abstract}
Joint probability density function (JDF) for non-normal random variables was derived by bivariate normal distribution function. From this JDF, the referenced strength, the 5th percentile of the strength distribution with $75 \%$ confidence level, for each grade of stress graded lumbers was calculated, assuming modulus of elasticity (MOE) as Normal distribution and modulus of rapture (MOR) as 2P. Weibull distribution. And the referenced strength was also calculated by Monte Carlo simulation using linear regression analysis by weighted residue (LRA). These values were compared. The results are as follows.

(1) The difference between these values depends on species. For example, in Douglas-fir and Dahurian larch they are relatively similar because the standard error by LRA of these species is relatively large. But for some species having small standard error, the difference is relatively large.

(2) In lower grades than mean MOE, the referenced strength by LRA method is larger than that by JDF method, but in higher grades the situation is reverse. The reason is that the standard error is proportional to $\sqrt{\mathrm{MOE}}$ and the standard deviation of MOR in lower grades is small and that in higher grades is large.

JDF method is really true from the probabilistic and statistical point. So it is hoped to recalculate load and resistance factors for stress graded lumbers in the Recommendation for Limit State Design of Timber Structures(draft) by JDF method.
\end{abstract}

\section{Keywords : joint probability density function, non normal random variable, stress graded lumber, referenced strength 同時確率密度関数、非正規変数、機械等級区分材、基準強度}

1.はじめに

「木質構造限界状態設計指針（案）・同解説」)では、設計点之荷 重および強度の公称值から算出した部分安全係数を用いた、荷重· 而力係数倍設計を採用している。同指針（案）では、機械等級区分 材、目視等級区分材に係わらず、耐力の分布を $2 \mathrm{P}$ ワイブル分布と し、変動係数の值に応じて荷重・耐力係数を算出し、設計者が適切な 值を選べるようにしてある。しかし、機械等級区分材の場合、曲げ ヤング係数（MOE）值の範囲により強度分布が規定されるが、同指 針（案）ではこのことを考虑していない。この問題は、MOE と強度 の同時確率密度関数に関し、MOE 值の範囲で制限された強度分布を 用いて、荷重・耐力係数を算出することができれば解决する。

また、荷重・耐力係数を算出するためには、強度の公称值=基準強 度が必要であり、機械等級区分材の曲げ強度（MOR）に関する基準 強度=信頼水凖 $75 \%$ に打汀る $5 \%$ 下限值（TL 値）の算出方法は、次 に示すような方法が考光れれるただし、以下のいずれの方法も、 実大材の強度試験デー夕に基づいている。

1) バンド法 ${ }^{2)}$ : MOE 值の範囲を決め、その範囲に含まれるデータ

の MOR 值の分布から TL 值を算出する。

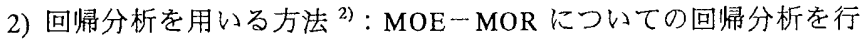

い、必要であれば重み付けをした回帰直線から TL 值を算出する。 3) モンテカルロシミュレーションを用いる方法 ${ }^{2)}$ :2) の回帰分析を 用い、仮想の MOE-MOR を発生させ、MOE 值の範用に含まれる発 生值から TL 值を算出する。

4) 同時確率密度関数を用いる方法：MOE-MOR についての同時確 率密度関数を用いて、MOE 值の上下限值で挟まれた範囲における TL 值を算出する。

しかし、各番号の方法に対して、以下の問題点もあげられる。 1) MOE 值の範囲におけるデー夕数が少ない場合、算出された TL 值の信頼性が低い。2) MOE 值の篭囲のどの值を代入すれば 5\%下限 值となるのか分からない。2,3) 回帰分析そのものが残差標準偏差を 正規分布と仮定しており、残差標準偏差の重㸚合わせが MOR とな るのであるから、MORの分布も正規分布となってしまう。しかし、 MOR が正規分布以外の分布にフィットした場合、整合性が取れな い。また、重みの根拠についての理論的な赛付けがない。1〜4) 実 大材の強度試験デ一タが、必ずしも母集団を表していないかも知れ ない。

確率・統計学的観点から正しい手法は4)であるが、上述した問 題点も存在する。しかし、どのような場合にも得られるデー夕の数
$*$ 新潟大学農学部応用生物化学科 教授・農博

** 木質構造研究所 代表・農博

**** 秋田県立大学木材高度加工研究所 教授・農博
Prof., Dept. of Applied Biological Chemistry, Faculty of Agriculture, Niigata Univ., Dr. Agr.

Director, Timber Engineering Institute, Dr. Agr.

Prof., Institute of Wood Technology, Akita Prefectural Univ., Dr. Agr. 
には限度があること、また、いずれの方法に扝いても MOEや MOR の分布が最もフィットした経験分布を母集団と考えていることを考 慮すれば、この点は問題とはならないであろう。したがって、4)に 示した同時確率密度関数を用いて、TL 值を算出することが最善と考 えられる。

以上概観してきたように、機械等級区分材における限界状態設計 では、MOE と MOR の同時確率密度関数を用いることが望まれる。 しかし、定式化されている同時確率密度関数は正規分布に関しての ものであり、MOEやMORが非正規変数の場合の定式化については、 近似式が示されている ${ }^{3)}$ もの、同文献に示されている原著論文 ${ }^{4)}$ でもどのようして求めたのか式の展開がなされておらず、今後の研 究の発展のためには式の展開がなされる心゙きと考える。

そこで、非正規変数に関する同時確率密度関数を誘導し、これを 用いて各機械的等級区分材に㧍ける基準強度を求め、デ一夕の都合 上、上述したバンド法を除いた手法により求めた值と比較し、両者 の間にどの程度の差異があるかを明らかにした。

\section{2. 非正規変数に関する同時確率密度関数の誘導}

$2 \supset$ 確率变数 $X 、 Y$ を正規分布、相関係数を $\rho$ とし、 $X 、 Y$ の平 均拉よび標準偏差をそれぞれ $\mu_{X} 、 \mu_{Y}$ および $\sigma_{X} 、 \sigma_{Y}$ とすれば、同 時確率密度関数は次式で表される。

$$
\begin{aligned}
& f(x, y)=\frac{1}{2 \pi \sigma_{X} \sigma_{Y} \sqrt{1-\rho^{2}}} \cdot \exp \left[-\frac{1}{2\left(1-\rho^{2}\right)}\right. \\
& \left.\left\{\left(\frac{x-\mu_{X}}{\sigma_{X}}\right)^{2}-2 \rho\left(\frac{x-\mu_{X}}{\sigma_{X}}\right)\left(\frac{y-\mu_{Y}}{\sigma_{Y}}\right)+\left(\frac{y-\mu_{Y}}{\sigma_{Y}}\right)^{2}\right\}\right]
\end{aligned}
$$

次に、2つの非正規変数 $X_{1} 、 X_{2}$ について、それぞれの累積確率分布 を $F_{X 1}\left(x_{1}\right) 、 F_{X 2}\left(x_{2}\right)$ 、確率密度関数を $f_{X 1}\left(x_{1}\right) 、 f_{X 2}\left(x_{2}\right)$ 、相関係数を $\rho_{12}$ とし、同時確率密度関数を誘導する。

(1) まず、確率変数 $X_{1} 、 X_{2}$ の任意の值において、累積確率および確 率密度の值が等しい等価な正規変数のパラメータをそれぞれ $m_{X 1}$ 、 $m_{X 2}$ および $s_{X 1} 、 s_{X 2}$ とすると、次式が成り立つ。ただし、 $\Phi(\cdot)$ は標凖 正規累積分布関数、 $\phi(\cdot)$ 漂準正規確率密度関数を表す。

$\Phi\left(\left(x_{1}-m_{X 1}\right) / s_{X 1}\right)=F_{X 1}\left(x_{1}\right)$

$x_{1}$ で微分して $1 / s_{X 1} \phi\left(\left(x_{1}-m_{X 1}\right) / s_{X 1}\right)=f_{X 1}\left(x_{1}\right)$

$\Phi\left(\left(x_{2}-m_{X 2}\right) / s_{X 2}\right)=F_{X 2}\left(x_{2}\right)$

$x_{2}$ で微分して $1 / s_{X 2} \phi\left(\left(x_{2}-m_{X 2}\right) / s_{X 2}\right)=f_{X 2}\left(x_{2}\right)$

(2) 次ざに、 $z_{1}=\left(x_{1}-m_{X 1}\right) / s_{X 1} 、 z_{2}=\left(x_{2}-m_{X 2}\right) / s_{X 2} 、 X_{1}$ 、

$X_{2}$ の相関係数を $\rho_{0,12}$ とし、(1)式を $X_{1} 、 X_{2}$ を用いて表したのが次式

である。

$$
\begin{aligned}
& f\left(x_{1}, x_{2}\right) \\
& =\frac{1}{2 \pi \dot{s}_{X 1} s_{X 2} \sqrt{1-\rho_{0,12}{ }^{2}}} \cdot \exp \left[-\frac{1}{2\left(1-\rho_{0,12}{ }^{2}\right)} .\right.
\end{aligned}
$$

$$
\begin{aligned}
& \left\{\left(\frac{x_{1}-m_{X 1}}{s_{X 1}}\right)^{2}-2 \rho_{0,12}\left(\frac{x_{1}-m_{X 1}}{s_{X 1}}\right)\left(\frac{x_{2}-m_{X 2}}{s_{X 2}}\right)\right. \\
& \left.\left.+\left(\frac{x_{2}-m_{X 2}}{s_{X 2}}\right)^{2}\right\}\right] \\
& =\frac{1}{2 \pi \sqrt{1-\rho_{0,12}}} \cdot \exp \left[-\frac{1}{2\left(1-\rho_{0,12}{ }^{2}\right)}\right. \\
& \left.\cdot\left\{z_{1}{ }^{2}-2 \rho_{0,12} z_{1} z_{2}+z_{2}{ }^{2}\right\} \cdot \frac{f_{X 1}\left(x_{1}\right)}{\phi\left(z_{1}\right)} \cdot \frac{f_{X 2}\left(x_{2}\right)}{\phi\left(z_{2}\right)}\right] \\
& =\phi\left(z_{1}, z_{2}, \rho_{0,12}\right) \cdot \frac{f_{X 1}\left(x_{1}\right)}{\phi\left(z_{1}\right)} \cdot \frac{f_{X 2}\left(x_{2}\right)}{\phi\left(z_{2}\right)}
\end{aligned}
$$

ただし、

$$
\begin{aligned}
& \phi\left(z_{1}, z_{2}, \rho_{0,12}\right) \\
& =\frac{1}{2 \pi \sqrt{1-\rho_{0,12}{ }^{2}}} \\
& \quad \cdot \exp \left[-\frac{1}{2\left(1-\rho_{0,12}{ }^{2}\right)} \cdot\left\{z_{1}^{2}-2 \rho_{0,12} z_{1} z_{2}+z_{2}{ }^{2}\right\}\right]
\end{aligned}
$$

である。

(3) 定義より、確率変数 $X_{1} 、 X_{2}$ に関する相関係数 $\rho_{12}$ は、それぞ れの変数の平均および標準偏差を $\mu_{X 1} 、 \mu_{X 2}$ および $\sigma_{X 1} 、 \sigma_{X 2}$ とす れば、次式で算出される。

$\rho_{12}=E\left\{\left(\frac{x_{1}-\mu_{X 1}}{\sigma_{X 1}}\right) \cdot\left(\frac{x_{2}-\mu_{X 2}}{\sigma_{X 2}}\right)\right\}$

一方、確率変数 $X 、 Y$ の関数 $h(x, y)$ に関する期待值の定義より、 $x$ と $y$ の同時確率密度関数を $f(x, y)$ とすれば、

$E\{h(x, y)\}=\int_{-\infty}^{\infty} \int_{-\infty}^{\infty} h(x, y) \cdot f(x, y) d x d y$

と表される。 $h(x, y)=\left(\left(x_{1}-\mu_{X 1}\right) / \sigma_{X 1}\right) \cdot\left(\left(x_{2}-\mu_{X 2}\right) / \sigma_{X 2}\right)$ と考 えれば、

$\rho_{12}=$

$\int_{-\infty}^{\infty} \int_{-\infty}^{\infty}\left(\frac{x_{1}-\mu_{X 1}}{\sigma_{X 1}}\right) \cdot\left(\frac{x_{2}-\mu_{X 2}}{\sigma_{X 2}}\right) \cdot f\left(x_{1}, x_{2}\right) d x_{1} d x_{2}$

である。(3)式を(5)式に代入すれば、

$$
\begin{aligned}
\rho_{12}= & \int_{-\infty}^{\infty} \int_{-\infty}^{\infty}\left(\frac{x_{1}-\mu_{X 1}}{\sigma_{X 1}}\right) \cdot\left(\frac{x_{2}-\mu_{X 2}}{\sigma_{X 2}}\right) \\
& \cdot \phi\left(z_{1}, z_{2}, \rho_{0,12}\right) \cdot \frac{f_{X 1}\left(x_{1}\right)}{\phi\left(z_{1}\right)} \cdot \frac{f_{X 2}\left(x_{2}\right)}{\phi\left(z_{2}\right)} d x_{1} d x_{2}
\end{aligned}
$$

となる。さらに、(2)式より 


$$
\begin{aligned}
& \frac{1}{s_{X 1}} d x_{1}=\frac{f_{X 1}\left(x_{1}\right)}{\phi\left(z_{1}\right)} d x_{1}=d z_{1} \\
& \frac{1}{s_{X 2}} d x_{2}=\frac{f_{X 2}\left(x_{2}\right)}{\phi\left(z_{2}\right)} d x_{2}=d z_{2}
\end{aligned}
$$

であるから、これらを代入して、結局

$$
\begin{gathered}
\rho_{12}=\iint\left(\frac{x_{1}-\mu_{X 1}}{\sigma_{X 1}}\right) \cdot\left(\frac{x_{2}-\mu_{X 2}}{\sigma_{X 2}}\right) \\
\cdot \phi\left(z_{1}, z_{2}, \rho_{0,12}\right) \cdot d z_{1} d z_{2}
\end{gathered}
$$

と表すことができ、(2)で述べた $\rho_{0,12}$ は、(6)式を満足する值であるこ とが分かる。したがって、非正規変数 $X_{1} 、 X_{2}$ についての同時確率密 度関数は次式で表すことができる。

$$
f\left(x_{1}, x_{2}\right)=\phi\left(z_{1}, z_{2}, \rho_{0,12}\right) \cdot \frac{f_{X 1}\left(x_{1}\right)}{\phi\left(z_{1}\right)} \cdot \frac{f_{X 2}\left(x_{2}\right)}{\phi\left(z_{2}\right)}
$$

ただし、 $\phi\left(z_{1}, z_{2}, \rho_{0,12}\right)$ は(4)式で表され、 $\rho_{0,12}$ は(6)式を満足する 值である。

\section{3、各機械等級区分材における基準強度の算出}

3. 1 対象とした樹種およびデータ

文献 1) pp.320に収集されたデー夕を用いた。樹種は、スギ (Cryptomeria japonica)、エゾマツ (Picea jezoensis)、トドマツ (Abies sachalinesis)、ダフリカカラマツ (Larix gmelini)、カラマツ (Larix leptolepis)、アカマツ (Pinus densiflora)、ヒノキ(Chamaecyparis obtusa)、ベイマツ (Pseudotsuga menziesii)、ヒバ (Thujopsis dolabrata) である。実大材の曲げ試験から得られた MOE、MORの值を ASTM-D2915 の換算式によって、含水率 15\%時の值に調整して解析 を行った。ここでは同時確率密度関数を用いることから、100\%のデ 一夕に対して分布を設定する必要がある。100\%データフィットの場 合、対数正規分布が適当であるという結果 ${ }^{4)}$ もあるが、文献 1)では

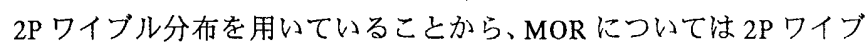
ル分布とした。また、MOE については、100\%データにフィットす る正規分布を仮定した。それぞれの分布パラメー夕法榡法により 算出した。表.1に樹種ごとの MOE、MOR の平均と変動係数の值を 示した。

\section{2 同時確率密度関数を用いた基準強度の算出}

前節で示した樹種に対し、MOR および MOEをそれぞれ 2P ワイ ブル分布、正規分布とした非正規確率変数に関する同時確率密度関 数を用いて、各等級区分における基準強度を算定した。例として、 スギに関する同時確率密度関数を図.1 示したが、例えば E70であれ ば、図.2に示すように下限値 $5.9\left(\mathrm{kN} / \mathrm{mm}^{2}\right)$ 上限值 $7.8\left(\mathrm{kN} / \mathrm{mm}^{2}\right)$ で区切り、経験分布にフィットしないで、この部分（図.3参照）に おける下側 5\%值に当たる強度値を基準強度とした。算出した基準 強度を表.2に示した。す心゙ての樹種に対し、MOR および MOEをそ れぞれ 2P ワイブル分布、正規分布としているので、図.1 および 2 に示した、同時確率密度関数や上下限值で区切られた分布の様子は、
すべての樹種で同様であった。

表 1 MOE および MOR における平均と变動係数

\begin{tabular}{|c|c|c|c|c|}
\hline \multirow{2}{*}{ 樹 種 } & \multicolumn{2}{|c|}{ MOE } & \multicolumn{2}{c|}{ MOR } \\
\cline { 2 - 5 } & $\begin{array}{c}\text { 平均 } \\
\left(\mathrm{kN} / \mathrm{mm}^{2}\right)\end{array}$ & $\begin{array}{c}\text { 変動 } \\
\text { 係数 }\end{array}$ & $\begin{array}{c}\text { 平均 } \\
\left(\mathrm{N} / \mathrm{mm}^{2}\right)\end{array}$ & $\begin{array}{c}\text { 変動 } \\
\text { 係数 }\end{array}$ \\
\hline スギ & 7.2 & 0.25 & 37.6 & 0.22 \\
\hline エゾマツ & 9.8 & 0.17 & 39.4 & 0.24 \\
\hline トドマツ & 9.2 & 0.15 & 38.2 & 0.22 \\
\hline ダフリカラマツ & 12.7 & 0.18 & 51.7 & 0.27 \\
\hline カラマツ & 8.7 & 0.21 & 39.4 & 0.27 \\
\hline アカマツ & 8.6 & 0.24 & 37.4 & 0.31 \\
\hline ヒノキ & 10.6 & 0.12 & 49.4 & 0.21 \\
\hline ベイマツ & 11.0 & 0.26 & 45.6 & 0.34 \\
\hline ヒバ & 8.8 & 0.14 & 41.0 & 0.19 \\
\hline
\end{tabular}

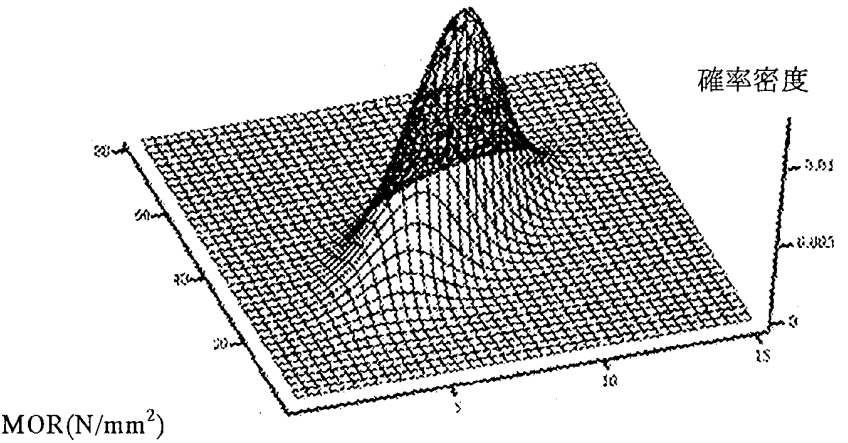

$\operatorname{MOE}\left(\mathrm{kN} / \mathrm{mm}^{2}\right)$

図 1 スギにおける同時確率密度関数

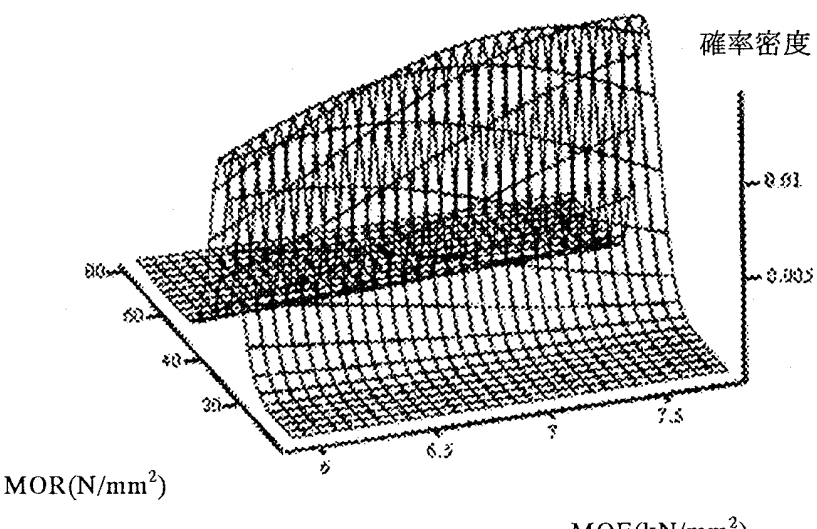

$\operatorname{MOE}\left(\mathrm{kN} / \mathrm{mm}^{2}\right)$

図 2 スギE70における同時確率密度関数

\section{3互み付け回昂直練分析を用いた基华強度の算出}


回帰分析は MOR の残差標準偏差を一定とする場合が一般的であ るが、乱数を発生させると MOE の傎が小さいところで負の MOR がかなり出現してしまう。そこで、文献 2)にある、残差標準偏差が MOE の平方根に比例する場合について、次式を用いて TL 值を算出 した。

\section{$\mathrm{TL}=a+b \cdot \mathrm{MOE}-K \cdot \mathrm{Se} \cdot \sqrt{\mathrm{MOE}}$}

ただし、 $a 、 b$ は回帰係数、Se は残差標準偏差、 $K$ は信頼限界係数で ある。3.1 で MOE にフィットさせた正規分布を母集団と考元、 $K=1.645$ とした。

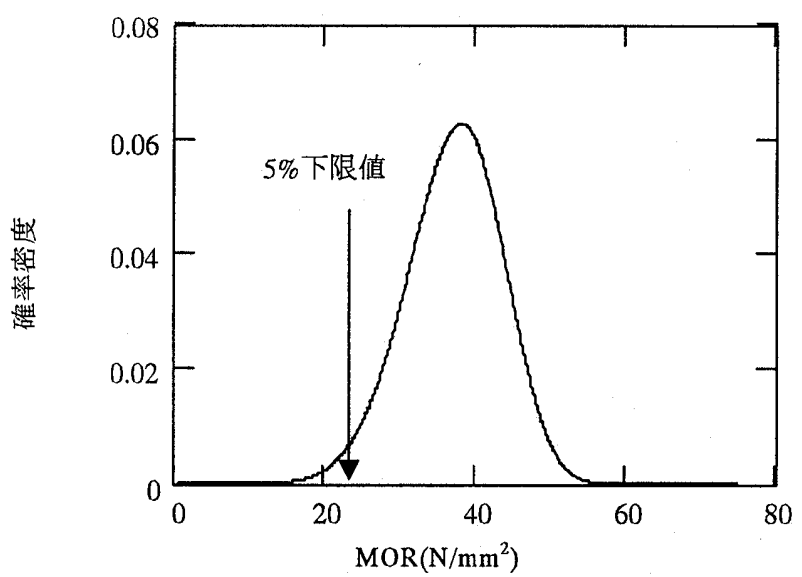

図 3 スギE70における確率密度関数

\section{4 シミュレーションを用いた基準強度の算定}

3.3 で得られた回帰分析結果を用いた。また、文献 2)に倣い、各 等級における MOR を 10,000 発生させ、界順に並べたときの 500 番 目の值を下側 $5 \%$ 值として求め、表. 2 に示した。ただし、残差標準 偏差が MOE の平方根に比例する場合、ベイマツおよびダフリカカ ラマツの E50において、負の MOR がそれぞれ 15 個、8 個発生して しまったが、それらを除いた発生個数における下側 $5 \%$ に相当する のはそれぞれ 499.25 番目および 499.6 番目なので、500 番目の值を 採用した。

\section{4. 結果と考察}

非正規変数に関する同時確率密度関数を用いて、MOR を $2 \mathrm{P}$ ワイ ブル分布、MOE を正規分布とした場合、機械等級区分材に対し、各 等級における基準強度を算出し、重み付汀回帰直線分析による方法 およびモンテカルロシミュレーションによる方法から得られる值と 比較した。その結果、次のことが分かった。

（1）重み付け回帰直線分析を用いた方法による值と、同時確率密度 関数による方法で算出した值は、樹種によってはかなり異なってい る。例㫕ば、ベイマツとダフリカカラマツにお汀る両者の值は比較 的近いが、これは重み付け回帰直線の残差標些偏差が大きいためで あり、他の樹種では残差標準偏差が小さく、両者の值にかなり大き な差が見られるものがある。

(2) MOE が平均值より小さい等級では、重み付け回㷌直線分析を用 いた值より同時確率密度関数を用いた方が小さく、平均值より大き い等級では逆になっている。これは、重み付汁回帰直線分析では残 差標準偏差を MOEの平方根あるいは MOEに比例させているので、
MOE の小さい等級では MOR の標準偏差が小さく、大きい等級では 大きくなってしまうためである。また、残差標準偏差の仮定により、 かなり大きな違いが生じている樹種も存在している。

文献 1)では、機械等級区分材における変動係数に対応して荷重・ 耐力係数が算定されているが、以上示して来たことから考光ると、 変動係数ではなく、樹種によって係数が異なる可能性がある。した がって、今後各樹種に対して、荷重・耐力係数を算定し、文献 1)で 算定した值と比較する必要があろう。

表 2 方法の違いによる基準強度

\begin{tabular}{|c|c|c|c|c|c|c|c|c|c|}
\hline \multirow{2}{*}{ 等級 } & \multicolumn{3}{|c|}{ スギ } & \multicolumn{3}{|c|}{ エソママツ } & \multicolumn{3}{|c|}{ トドマツ } \\
\hline & RA1 & RA2 & JDF & A1 & RA2 & JDF & AA1 & RA2 & $\mathrm{JDF}$ \\
\hline E50 & 23.1 & 22. & 19. & & 12.6 & & 5.0 & 12.9 & 11.3 \\
\hline E70 & 7.1 & 26.9 & 2 & & 18.5 & & 0.8 & 19.5 & \\
\hline E90 & 1.7 & 31.5 & 32. & 5.4 & 24.6 & & .1 & 26.2 & 25.7 \\
\hline E110 & 6.2 & 36.1 & 39 & 2.0 & 30.8 & 31. & 2 & 33.0 & 53 \\
\hline E130 & 1.0 & 40.9 & 4 & & 37.2 & & 9.7 & 40.0 & 41.1 \\
\hline E150 & 45.7 & 45.8 & 50.1 & 5.2 & 43.6 & 45.7 & 46.5 & 47.0 & 48 \\
\hline \multirow{2}{*}{ 等級 } & \multicolumn{3}{|c|}{ ダフリカカラマツ } & \multicolumn{3}{|c|}{ カラマツ } & \multicolumn{3}{|c|}{ アカマッ } \\
\hline & RA1 & RA2 & JDF & RA1 & RA2 & JDF & RAl & RA2 & JDF \\
\hline E50 & 1 & 6.3 & 7.5 & 6.5 & 15.3 & 12.9 & 14.0 & 13.0 & 11 \\
\hline E70 & 15.5 & 13.9 & 12.8 & 2.0 & 21.3 & 19 & .2 & 18.5 & 17.1 \\
\hline E90 & 3.6 & 21.8 & 20.0 & 8.3 & 27.6 & 27. & 25.0 & 24.3 & 24 \\
\hline 8110 & .5 & 29.8 & 29 & 3 & 34.0 & 29 & & 30.2 & \\
\hline E130 & 9.3 & 37.9 & 38. & 40.7 & 40.5 & 42.7 & 36.7 & 36.3 & 39.0 \\
\hline 50 & & 46.1 & 4 & & 47.1 & 50 & & 42.4 & 46.6 \\
\hline \multirow{2}{*}{ 等級 } & \multicolumn{3}{|c|}{ ヒノキ } & \multicolumn{3}{|c|}{ ベイマツ } & \multicolumn{3}{|c|}{ ヒバ } \\
\hline & RA1 & RA2 & $\mathrm{J}$ & RA1 & RA2 & $\mathrm{JD}$ & $\mathrm{R}$ & RA2 & JDF \\
\hline E50 & 16.7 & 13.6 & 11 & 10.9 & 10.0 & & 21.3 & 19.3 & 15.8 \\
\hline E70 & 23.5 & 20.9 & 18.5 & 17.0 & 16.1 & 14.7 & 26.1 & 24.9 & 23.0 \\
\hline E90 & 30.5 & 28.5 & 27. & 23.6 & 22.5 & 21.4 & 31.1 & 30.6 & 30.3 \\
\hline E110 & 37.1 & 36.2 & 36.2 & 30.3 & 29.1 & 29.1 & 36.3 & 36.5 & 37.6 \\
\hline E130 & 44.1 & 44.0 & 45.4 & 37.0 & 35.8 & 37.5 & 42.1 & 42.5 & 44.5 \\
\hline 150 & 51.6 & 51.9 & 54 & 43.7 & 42.6 & 46 & 4 & 48.6 & 50.8 \\
\hline
\end{tabular}

（注）RA1：シミュレーションによる方法、RA2：重み付き回帰淔 線による力法、JDF：同時確率密度関数による方法

\section{参考文献}

1) 日本建築学会 : 木質構造限界状態設計指針(案)·同解説、2003.

2）建設省建築研究所：建設省総合技術開発プロジエクト「新木造建 築技術の開発報告」、pp.12-68、1989.

3) Armen Der Kiureghian, Pei-Ling Liu: J. of Eng. Mechanics, 112(1), pp. $85-104,1986$.

4) Nataf, A.: Determination des Distribution don $t$ les marges sont Donnees, Comptes Rendus de l Academie des Sciences, 225, pp.42-43, 1962.

5) 䏱江和美、中村 昇、飯島泰男：日本木材学会誌、45(2)、 pp.103-10、 1999. 